\title{
Forensic Aspects of Fluorine Poisoning
}

\author{
DRAGOS CRAUCIUC ${ }^{1}$, MIHNEA COSTESCU2*, CALIN SCRIPCARU3*, SIMONA IRINA DAMIAN ${ }^{2 *}$, CARMEN CORINA RADU4, \\ NONA GIRLESCU ${ }^{1}$ \\ ${ }^{1}$ Grigore T.Popa University of Medicine and Pharmacy, 16 Universitatii Str., 700115, Iasi, Romania \\ ${ }^{2}$ Carol Davila University of Medicine and Pharmacy, Discipline of Pharmacology and Pharmacotherapy, 8 Eroii Sanitari Blvd.050474, \\ Bucharest, Romania \\ ${ }^{3}$ Stefan cel Mare University of Suceava, Institute of Legal Medicine of lasi, 4 Buna Vestire Str., 700455, lasi, Romania \\ ${ }^{4}$ University of Oradea, Faculty of Medicine and Pharmacy, 1 Universitatii Str., 410087, Oradea, Romania
}

\begin{abstract}
In medical literature, existing studies show the opportunity to use fluorine for one's health. The presence of this substance in the normal composition of all tissues and organs of the human body as well as deficiencies highlighted under certain circumstances support this aspect. They show both the positive effects of fluorine, such as the role of fluorine in increased calcium storing in the bones and teeth, and the negative effects, for example inhibition of phosphatases, (enzymes used in many metabolic processes). The double effect also appears in the use of fluorine in treatments, because when overcoming a critical threshold for the body it may produce adverse effects, sometimes leading to death. The present article analyzes these effects, the primary purpose being to raise awareness and identify the reactions of fluorine on the body.
\end{abstract}

Keywords: fluorosis, toxicity, studies, ingested

In 1771 Carl Wilhelm Scheele discovered fluorine, in the form of a non-metal noble gas. Later, in 1886 a French chemist, Henri Moisann, after successive attempts, managed to isolate it. Many other chemists tried to isolate fluorine before Farraday Davy, some of whom died poisoned with this substance [1], as in other situations, until a methodology regarding the approach and prevention of this substance was established, there have been deaths due to various types of gas or substances that were accidentally or willingly ingested, or during a scientific experiment [26]. Fluorine is a greenish-yellow gas, with a particularly strong odour. It is highly corrosive and reactive. Hydrofluoric acid, one of the fluorine-reactive compounds, is used in engraving because of the ease with which it attacks glass.

Fluoride is spread in all elements of the environment soil, water, air, food, most often in the form of mineral or organic fluorides, sometimes in the form of ions, and very rarely in its natural form.

Water is an essential source of fluorine for the human body because its absorption is superior to food sources. Fresh surface waters are the poorest in fluorine content (0.01-0.3 mg F- / L), whereas underground waters contain higher concentrations ( $0.1-25 \mathrm{mg} \mathrm{F}$ - / L).

In many countries around the world, research has shown the low fluorine content in water sources [7]. In our country the waters have fluorine deficiency, over $60 \%$ of the water sources having concentrations below $0.35 \mathrm{mg} / \mathrm{L}$ [8].

Although fluorine is more toxic than lead and very close to arsenic as toxicity, it is added to drinking water. Since 1930 research has shown that in small amounts fluorine helps to prevent tooth decay. This led to the initiation of campaigns promoting fluorine use for which such positive effects were confirmed. As a consequence, fluorine was introduced into oral hygiene procedures, in toothpaste, in mouthwash as sodium fluoride. Gerald J. Cox, (who was neither a doctor nor a dentist, was the precursor of this fact, being actually employed by an aluminum producing company, the ALCOA Foundation [9].

It should also be known that sodium fluoride is a residual material in the aluminum industry and is also used as an element in cockroach and rat poison.

\section{Importance for organism}

In the period of time between 1986 and 1987, the American Dental Research Institute initiated a study that enrolled 39,000 subjects aged between 5 and 17, divided into three categories:

-the first category - subjects who lived in areas where water was fluorinated,

-the second category - was represented by subjects who had consumed partially fluorinated water

-the third category - subjects living in areas where the water had not been fluorinated.

The study concluded that there were no notable differences between fluorinated and non-fluorinated areas.

Still, in 1988, The Argon National Laboratory confirms that fluorine can turn normal cells into cancer cells. Although the discovery was alarming, few countries have taken action in this aspect [10].

In 1977, P.D. Oldham and D.J. Newell established in a study published in Applied Statistics, a causal link between water fluorination and cancer. Their conclusions are supported by the study conducted by I.A. Disney, and was reported in 1990 in Community Dentistry and Oral Epidemiology, on fluorinated water in schools. It is also worth mentioning the work of M.C. Mahoney called Incidence rate of bone cancer in New York, published in The American Journal of Public Health in 1991, and S. E. Hrudley's Fluorination of drinking water and osteosarcoma written in 1990 and published in The Canadian Journal of Public Health. One of the very important conclusions that emerged from these scientific reports was that the effects of fluoridation may have repercussions over generations, leading to the birth of children without bones or skull.

Procter \& Gamble conducted a study in 1991 demonstrating that only half the recommended amount of fluoride increases the risk of genetic problems. Later, in 1993, the United States Institute of Science, Health and Environment supports this conclusion. The derivative used in toothpaste, in pills, including drinking water, is sodium fluoride [10-12].

In Canada, another study conducted by the University of Toronto has shown a strong causal link between hip

\footnotetext{
*email:mihneacostescu@yahoo.com; calinscripcaru@yahoo.com; si_damian@yahoo.com
} 
fractures and water consumption in areas where fluorine is present in water. It seems that fluorine causes the bones to become more fragile, more prone to fractures or orthopedic problems [8]. New England J ournal of Medicine published in March 1990 a study that confirmed increased bone fractures in patients with osteoporosis following fluorine consumption.

The research carried out over the years in our country on the content of microelements in different water sources has revealed an iodine and fluoride deficiency with consequences on people's health namely an increased incidence of endemic goitres and dental decay in some territories, thatis whyin Romania the problem of fluoridation of drinking water has not been addressed so far [8].

Fluorine is part of the normal composition of all body tissues and organs, the richest in fluorine being the bones and teeth (enamel and dentin). This element is also found in the brain, liver, thyroid, teguments.

In the body, fluorine has two major categories of roles, structural roles, being part of bone and teeth structure and functional roles, interfering with the activity of some important enzymes. Regarding the structural role, many studies have revealed fluorine intervention in increased calcium deposits, both in the bones and teeth [9, 13-15]. So, these tissues are consolidated not only due to the fact that fluorine is part of the constituent Fluor apatite structure, more resistant than apatites without fluorine (which are also found in bones and teeth), but also because fluorine causes the increase of calcium concentration at their level [16].

Regarding the functional roles exerted on enzymes, it is worth noting the positive interventions - fluorine being the inhibitor of some enzymes involved in the glycolytic degradation of glucose, which contributes to the preservation of tooth integrity, but also the negative ones. In high concentrations fluorine inhibits phosphatises enzymes that are important in many metabolic processes.

Of the amount of fluoride fixed in hard tissues, a relatively small part is eliminated from the body, so fluorine is considered an element with long retention in the body [16].

\section{Fluorine metabolism}

Fluorine, an indispensable elementfor the development of the human body, is the only organically anchored element and is identified in $99 \%$ of the apatite netw ork of bone and tooth tissue. The remaining $1 \%$ is found in the blood, brain, and muscle.

The presence of fluorine in the body is accomplished by food and water intake. Fluorine intake happens very rarely, incidentally, on an exceptional basis through breathing. Fluorine is found in nature in the form of chemical compounds, and not as a stand-alone element. We can find it in our body especially in the dental structures.

We are most interested in the fluorine you can find in water and food. We ingest about 0.2-0.6 mg daily through food. Large amounts of fluorine can be found in tea leaves, seaweed, beef liver, paddy rice, salt water fish and saltwater. Water has variable fluorine content. In Romania, $90 \%$ of the water sources are low in fluorine.

Resorption occurs in the small intestine, almost entirely dependent on the ion accompanying fluorine, whether magnesium, aluminum, iron or calcium. Total resorption or over $80 \%$ occurs in combination with sodium or phosphorus.

Subsequent to absorption, $99 \%$ of fluorine is transported by the blood to the hard tissues (bones and teeth) and 1\% to the soft tissues. Soft tissues do not accumulate fluorine, so increasing consumption of this substance will produce high accumulations in bones and teeth, depending on age and period of administration. There are also differences in fluoride accumulations in the bones and in the teeth. The bones store the fluorine ions permanently, continuously refreshing the contents, while at the tooth level fluorine accumulation has temporary, limited effect. Half of the amount ingested daily is eliminated by the kidneys, very little by saliva and sweating.

Water fluoridation is the most commonly used method due to the following advantages:

- drinking water brings the highest fluoride intake to the body (2/3-3/4 of the daily quantity needed by an adult),

- is consumed in relatively constant quantities by all members of the community ( 1 - $2 \mathrm{~L}$ water / day). Fluorine in water is found as soluble compounds easily absorbed in the body.

Water fluoridation uses sodium fluoride (most commonly), magnesium fluoride, fluorosilicic acid, etc.

Defined in the early 1950s as a method of "mass prevention of dental caries", fluoridation of drinking water has been applied and is still being applied in many parts of the world and it contributed to the decrease in incidence of dental caries in the fluoridated water consuming population, with greater effects as this prophylactic measure was applied at a younger age [10].

Water fluoridation is recommended provided the fluorine level in the water to the consumer is within optimal limits $(0.8-1.2 \mathrm{mg} / \mathrm{L})$ and is permanently monitored.

Water fluoridation has been used worldwide, with hundreds of millions of people benefiting from fluoridecontaining water with notable results in decreasing the incidence of dental decay [7].

In recent years, there have been many criticisms of potable water fluoridation that draw attention to the following aspects:

Accidental increase of fluorine concentration in fluorinated water with possible acute toxicity manifestations among consumers [17].

Excessive ingestion of fluorine can lead to dental fluorosis. According to data available at the United States Centers for Disease Control and Prevention, 32\% of children who drink fluoridated water have some forms of dental fluorosis, $2-4 \%$ of whom have severe stages of this disease [18].

Fluorine in drinking water ingested for a long time decreases children's intelligence (decreases IQ), memory and learning ability [19].

Population studies have shown that children who consume fluoridated water show an increased incidence of dental fluorosis and fractures. Excessive exposure to fluorine creates skeletal fluorosis, which is difficult to diagnose and can be easily mistaken for arthritis or rheumatoid arthritis [16, 17].

An increase in renal disease has been noticed in people who consume more than $2 \mathrm{mg} \mathrm{F} / \mathrm{L}$ or with lower concentrations for a long time.

In vitro studies have indicated that fluorine is a mutagen element. It is known that a compound with mutagenic properties also leads to cancer, in the case of fluorine in osteosarcoma, whose incidence is higher in areas with fluoridated water compared to the incidence of this disease in the population that consumes non-fluorinated water.

\section{Pros and cons of fluoridation}

At the beginning of the 21st century, the scientific world is divided in two: pro and against the effects of fluorine introduced into drinking water for the purpose of prophylaxis of dental caries. The legislation of many states increasingly 
prohibits the fluoridation of water from the centralized water supply system (Sweden, Germany), but in other countries it has never been applied (Denmark, Luxembourg, Austria). In July 2002, The Belgian Ministry of Health has forbidden the use of fluorine tablets and fluorine chewing gum, and the fluoridation of water is not allowed. However, in Ireland $75 \%$ of the water supplies are rich in fluorine. It is not surprising that in this country the osteoporosis rate is the highest in Europe [7].

Introducing fluorine in milk or using fluorine tablets are fluorine supplementation methods, especially for children.

Topical fluoroprophylaxis methods provide a cariostatic effect, the most commonly used being fluoride toothpaste, mouthwash solutions, topical applications.

A more recent study was conducted to evaluate dental fluorosis and compare incisive teeth fluorescence among school-aged children in the Nalgonda district, Andhra Pradesh. The transversal analytical study was conducted on a total of 1,000 school children aged between 13 and 15 , who were selected by taking samples of water from 4 different areas with different levels of fluorine in drinking water. Fluorose was recorded using the TF (TFI) index. Fluorose prevalence (TFI score e"1) was $100 \%$ for all 4 different levels of fluorine. Prevalence and severity increased with the increase in fluorine in drinking water. The prevalence and severity of fluorosis did not reveal significant variations between incisive and mandibular teeth. The conclusion of the study was that there was a high prevalence of mild to moderate fluorosis in the Nalgonda district, even in areas with optimal fluorine levels in water [19-21].

Fluoride is able to trigger some harmful effects through its pharmacodynamic properties.

In the US, the studies that were conducted by the National Institute of Cancer have revealed that ingesting fluoride increases the risk of all types of cancer by $5 \%$ (bone cancer in young people). Even in small amounts, fluorine inhibits many enzymes as it is highly active and it is mutagenic, causing genetic mutations at DNA level.

Some studies show that fluorine strengthens dental enamel and reduces the dental decay, but there are other studies that have shown that fluorine affects tooth health in a negative way, and it also has negative effects on the bone system. On the other hand, other studies have shown the connection between daily ingestion of sodium fluoride and certain health problems, such as: endocrine system damage, decreased IQ, concentration incapacity, lethargy, mental fatigue, blockade of melatonin secretion that lowers immunity, accelerates aging and causes sleep disturbances, calcification of the epiphysis with early onset of puberty, increased fractures, infertility.

Acute intoxication with fluorine is rare. Signs of acute fluoride poisoning are: nausea, vomiting, abdominal pain (cramps), circulatory and respiratory systems collapse, seizures, paresthesia. Continuous ingestion of high doses of natural fluorides leads to the occurrence of symptoms of chronic intoxication manifested by the occurrence of fluorosis: tooth changes (dental fluorosis - the first sign of toxicity) and bone changes (osteoporosis). Dental fluorosis is a disease that occurs after fluorine poisoning in children under 8 and does not advance after the tooth has grown, but during its development causes irreversible changes in the enamel (color - white spots or streaks, browns or ashess , but also of structure - the enamel has an unusual shape).

Multiway skeletal fluorosis may occur after a daily ingestion of 10-20 mg fluorine for 10-20 years/day. Osteoporosis occurs after a daily consumption of fluorine- containing drinking water in concentrations of $8 / 14 \mathrm{ppm}$ (parts per million) fluorine / $L$ over a long period of time. Generalized dental fluorosis occurs during teeth development (up to 8 years of age) as a result of the daily intake of $0.1 \mathrm{mg}$ fluorine / $\mathrm{kg}$ body weight / day.

The reference dose for fluorine poisoning is $5 \mathrm{mg}$ fluorine $/ \mathrm{kg}$ body weight. Fatal acute poisoning occurs in adults following ingestion of $2.5 \mathrm{~g}$ fluorine, and death will occur within 2-4 hours. For a child aged 1 to 1.5 , acute fluorine poisoning may occur after ingesting of $5 \mathrm{mg}-15 \mathrm{mg}$ fluorine $/ \mathrm{kg}$ body, the fatal acute dose being $250-320 \mathrm{mg}$ of fluorine (a tube of toothpaste, 200 tablets of fluoride of $0.25 \mathrm{mg}$ ). For a 3-year-old child the fatal acute dose is $435 \mathrm{mg}$ of fluorine, death occurring in about 3 hours.

\section{Conclusions}

The World Health Organization includes fluoride among the essential elements for the normal growth and development of the human body. At the same time, there is no human affection due to the deficiency of fluorine in the body. When administered under specialized supervision, fluorine is a safe supplement for the body, but it can also become a cumulative poison.

Drinking water is not fluorinated in Romania, but all dental care products contain fluorine (including toothpastes for very young children).

It is very important to know the total amount of fluorine in all products marketed for systemic use (tablets) and for topical use (toothpaste, mouthwash, tooth gels, etc.), as fluorinated these agents are harmless if used strictly according to medical indications.

Fluorine is beneficial in small quantities and toxic when ingested in large quantities. The double effect is manifested in overdose that can have fatal effects, so parents need to carefully monitor their children and keep their fluorine products away from them, especially until the age of 6 , the babies being prone to swallowing the toothpaste. Also, doctors prescribe fluorine supplements such as Zymaflor for children (daily from the age of several months to puberty). In such cases, rigorous parental information is advised on the beneficial and harmful effects of fluorine before administration.

\section{References}

1.CAMPOS, DH. Official Lies, Litera Int, 2008.

2.DUMBRAVA, D.P., RADU, C.C., IOV, T., DAMIAN, S.I., SANDU, I., TIMOFTE, D., CHIROBAN, O., An Unusual Case of Accidental Carbon Monoxide and Ethanol Intoxication in Two Commorientes Deaths, Rev.Chim.(Bucharest), 69, no.7, 2018, p. 1889-1891

3.CRAUCIUC, D.V., CRAUCIUC, E.G., IOV, C.) ., FURNICA, C., IOV, T., Non-invasive Evaluation of Neonatal Cerebral Status in the Newborns of Mothers Addicted to Alcohol and Drugs, Rev.Chim.(Bucharest), 69, no.11, 2018,p. 4088-4092

4.IOV, T, TIMOFTE, D, DAMIAN, SI, KNIELING, A, SCRIPCARU, C, BULGARU-ILIESCU, DB, Non-traumatic cervical hemorrhagic infiltration, ROMANIAN J OURNAL OF LEGAL MEDICINE, 2018, 26(2):141144

5.DAVID, S., KNIELING, A., DAMIAN, S.I., DIAC, M., SANDU, I., IOV, T., Study on Forms of Intoxication with Cocaine and Evolutionary Aspects, Rev.Chim.(Bucharest), 69, no.5, 2018, p.1216-1219

6.DUMBRAVA, D.P., RADU, C.C., DAVID, S., IOV, T., IOV, C.J ., SANDU, I., BULGARU ILIESCU, D., The Importance of Alcohol Testing by Gas Chromatography vs the Cordebard Classical Method Modified in the Medico Legal Investigation, Rev.Chim.(Bucharest), 69, no.9, 2018, p.2407-2410

7.***World Health Organization. Global strategies to reduce the health care burden of craniofacial anomalies. Geneva; 2002. 
8.***Report from the Commission to the Council and the European Parliament on the implementation of Council Directive 91/676 / EEC on the protection of waters against pollution caused by nitrates from agricultural sources for the period 2000-2003.

9.COX, GJ , MATUSCHAK, MC, DIXON, SF, DODDS, ML, WALKER, WE, Experimental Dental Cavities IV. Fluorine and its relation to dental cavities, J Dent Res 18 (1939) 481.

10.OLDHAM, PD, NEWELL, DJ. Fluoridation of water supplies and cancer - a possible association?, Applied Statistics, 1977, p.125-135.

11.FURNICA, C; KNIELING, A; DAMIAN, SI; DIAC, M; DAVID, S; BULGARU ILIESCU, D; SANDU, I; IOV, C.J., Fatal Ethylene Glycol Intoxication Secondary to Accidental Ingestion, Rev.Chim.(Bucharest), 68, no.7, 2017, p.1591-1594

12.BOWEN WH. Fluorosis: Is it really a problem? J Am Dent Assoc 2002; 133:1405-7.

13.WARREN JJ, LEVY SM, KANELLIS MJ . Prevalence of dental fluorosis în the primary dentition. J Public Health Dent 2001;61:87-91.

14.De LIEFDE, HERBISON GP. The prevalence of development defects of enamel and dental caries în New Zealand children receiving differing fluoride supplementation, în 1982 and 1985. N Z Dent J 1989; Jan 85(379): 2-8.
15.GRIFFIN SO, BELTRAN ED, LOCKWOOD SA, BARKER LK. Esthetically objectionable fluorosis attributable to water fluoridation. Community Dent Oral Epidemiol 2002;30:199-209.

16.MOLLER IJ. Fluorides and Dental Fluorosis. Int Dent 1982; 32: 134 147.

17.PETERSEN PE. Social inequalities in dental health towards a theoretical explanation. Community Dentistry and Oral Epidemiology, 1990; 18: 153-8.

18.WHELTON HP, KETLEY CE, MCSWEENEY F, O'MULLANE DM. A review of fluorosis în the European Union: Prevalence, risk factors and aesthetic issues. Community Dent Oral Epidemiol 2004;32:9-18. 19.HOWARD Hu. Higher levels of fluoride in urine associated with lower intelligence in children. University of Toronto, 2017.

20.SUDHIR KM , PRASHANT GM , SUBBA REDDY VV, MOHANDAS U, CHANDU GN. Prevalence and severity of dental fluorosis among 13to 15-year-old school children of an area known for endemic fluorosis: Nalgonda district of Andhra Pradesh. J of Indian Soc Pedodont Prev Dent, 2009, 27(4): 190-196.

21.UNTU, I, CHIRITA, R, BULGARU ILIESCU, D, DANIEL CHIRILA, B, CIUBARA, A, BURLEA, SL, Ethical Implications of Bio-Psycho-Social Transformations Entailed by the Aging Process, The J ournal of research and social intervention, volume 48 pg: 216-225

Manuscript received:18.08.2018 